Ю. И. Заседа, Шихалиев Ф. Б., Соломенный Р. И.

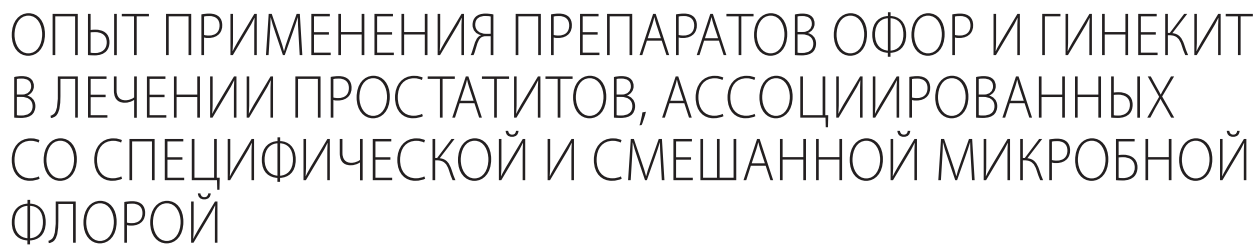

Клиника «Мужское Здоровье» г. Киев

Yu. I. Zaseda, Shyhaliev F. B., Solomianyi R. I.

\title{
EXPERIENCE OF USE OF OFOR AND GYNEKIT IN THE TREATMENT OF PROSTATITIS ASSOCIATED WITH SPECIFIC AND MIXED MICROBIAL FLORA
}

Clinic "Men's Health" Kiev

Резюме Цель исследования - установить эффективность использования препаратов «Офор» и «Гинекит» при последовательном сочетанном применении в терапии воспалительных заболеваний предстательной железы, ассоциированных со специфической и смешанной микробной флорой.

Материалы и методы. Проведено клиническое проспективное исследование, в котором приняли участие 30 пачиентов амбулаторного отделения клиники «Мужское Здоровье», страдающих воспалительными заболеваниями предстательной железы. В качестве методов исследования, помимо стандартного комплекса, были выбраны: IN POUCH TV-тест; Андрофлор (ПЦР метод); сонографическое исследование предстательной железы и спермограмма.

Результаты исследования. В исследовании установлено, что в общем контингенте клиническое выздоровление было зарегистрировано у 29 пациентов (96,7\% от общего контингента), лабораторное - в 27 случаях (90\% от общего контингента). Возврат симптоматики через 3 месяца был зарегистрирован у 2 пациентов (6,7\% от общего контингента).

Выводы. Уровень эффективности использование препаратов «Офор» и «Гинекит» в сочетании с комплексом вспомогательной фармако- и физиотерапии в отношении пациентов, страдающих воспалительными заболеваниями предстательной железы, ассоциированных со специфической и смешанной микробной флорой, достигает 96,7\%. Анализ этиологической вариабельности клинического эффекта указывает на наличие единичных случаев неполного эффекта данной терапевтической модели, при этиологии заболевания ассоциированной с Trichomonas vaginalis.

Ключевые слова: урология, предстательная железа, простатит, спермограмма.

Актуальность. Несмотря на значительный прогресс, достигнутый андроурологией, прежде всего, в её терапевтическом аспекте, некоторые патологические состояния урогенитальной локализации, по-прежнему представляют собой сложную клиническую проблему, разрешение которой требует поиска взвешенных решений $[2,8]$.
К таковым относятся воспалительные заболевания предстательной железы, ассоциированные со смешанной микробной флорой. Помимо специфической локализации, имеющей прямые пути инфицирования, данный класс патологии демонстрирует все общие тенденции инфекционных воспалительных заболеваний - наличие динамически изменяющейся анти- 
биотикорезистентости, зависимость характера поражения и течения заболевания от иммунного статуса и склонность к формированию смешанных патогенных и условно-патогенных популяций возбудителей [3, 6, 7].

Помимо этого, предстательная железа за счет интенсивной секреторной активности обеспечивает ряд уязвимых функций мочеполовой системы, что обеспечивает значительное влияние патологического процесса на её функционирование, не только драматически снижая качество жизни больного, но и приводя к трудно поддающимся коррекции осложнениям, как со стороны общего функционирования мочеполовой системы, так и оказывая выраженный негативный эффект на репродуктивные функции $[4,9]$.

Лечение воспалительных заболеваний предстательной железы, ассоциированных со смешанной микробной флорой, является сложной задачей, прежде всего в силу необходимости подбора этиотропной терапии, отвечающей критериям надежности и безопасности. На данный момент, тактика поиска антибиотика, который может быть использован в качестве монотерапии, все больше утрачивает перспективность. Причиной этому являются пропорции между широтой спектра действия и безопасностью, а также между возможностью преодоления антибиотикорезистентности и доступностью $[1,5]$.

На данный момент, перспективным представляется поиск эффективных терапевтических моделей, в рамках которых, в комплексную терапию данного класса патологии, будут интегрированы комбинации антибиотиков, имеющие высокие показатели надежности, безопасности и доступности.

Цель исследования: установить эффективность использования препаратов «Офор» и «Гинекит» при последовательном сочетанном применении в терапии воспалительных заболеваний предстательной железы, ассоциированных со специфической и смешанной микробной флорой.

Дизайн: исследование проведено в проспективном дизайне на базе клиники «Мужское Здоровье» на материале 30 пациентов, страдающих воспалительными заболеваниями предстательной железы.

При формировании контингента исследования был использован комплекс критериев включения и исключения.
Критерии включения:

- наличие диагноза в рамках рубрик МКБ10: N41.0 и N41.1;

- отсутствие противопоказаний к проведению антимикробной терапии, а также состояний индивидуальной непереносимости офлоксацина, орнидазола, азитромицина, секнидазола, флуконазола.

Критерии исключения:

- наличие осложнений, требующих хирургического лечения;

- наличие системных и онкологических заболеваний, ассоциированных с непредсказуемым прогнозом от антибиотикотерапии заболевания предстательной железы.

Bсе пациенты, вошедшие в контингент исследования, помимо стандартного комплекса лабораторных исследований, прошли дополнительные обследования:

- тест IN POUCH TV для выявления trichomonas vaginalis (производство Biomed Diagnostics, inc.);

- Андрофлор, исследование микрофлоры урогенитального тракта мужчин методом полимеразной цепной реакции (с целью идентификации микробной флоры - Lactobacillus spp., Streptococcus spp., Staphylococcus spp.; Corynebacterium spp., Mycoplasma hominis, Ureaplasma urealyticum. Ureaplasma parvum, Atopobium claster, Bacteroides spp., Porphyromonas spp., Prevotella spp., Anaerococcus spp., Peptostreptococcus spp., Parvimonas spp., Eubacterium spp., Haemophilus spp., Haemophilus spp., Pseudomonas aeruginosa, Ralstonia spp., Burkholderia spp., Enterobacteriaceae spp., Enterococcus spp., Candida spp., Mycoplasma genitalium, Trichomonas vaginalis, Neisseria gonorrhoeae, Clamydia trachomatis.

- сонографическое исследование предстательной железы (с целью оценки степени и характера поражения, исключения объемных образований, состояний дисплазии);

- спермограмма (с установления наличия патологических включений в сперме).

По результатам дополнительного обследования, из контингента исследования были исключены пациенты, у которых была обнаружена Clamydia trachomatis. 


\section{Результаты исследования}

Пациенты, вошедшие в контингент исследования, имели следующее распределение ассоциированной микрофлоры:

- Trichomonas vaginalis - 11 пациентов (36,7\% от общего контингента);

- Mycoplasma hominis / Ureaplasma urealyticum / Ureaplasma parvum - 4 пациента (13,3\% от общего контингента)

- анаэробная микрофлора Lactobacillus spp., Streptococcus spp., Staphylococcus spp.; Corynebacterium spp. - 5 пациентов $(16,7 \%$ от общего контингента);

- аэробная микрофлора, в частности: Atopobium claster, Bacteroides spp., Porphyromonas spp., Prevotella spp., Anaerococcus spp., Peptostreptococcus spp., Parvimonas spp., Eubacterium spp., Haemophilus spp., Haemophilus spp., Pseudomonas aeruginosa, Ralstonia spp., Burkholderia spp., Enterobacteriaceae spp., Enterococcus spp. - 10 пациентов (33,3\% от общего контингента).

Контингент исследования был условно разделен на этиологические группы для дальнейшего анализа эффективности используемой модели лечения. Вне зависимости от этиологии заболевания все пациенты проходили лечение в условиях стационара на протяжении 25 суток по следующей модели:

- «Офор» (Офлоксацин $200 \mathrm{mg}$ + Орнидазол 500mg) перорально по 1 таблетке 3 раза в день на протяжении 10 суток от начала лечения;

«Гинекит» (Азитромицин 1000 mg; Секнидазол 1000 mg; Флуконазол 150 mg) перорально по 1 таблетке 3 раза в день (утро - таблетка С, полдник - таблетка С, день - таблетка Ф, вечер - таблетка А) 1-е, 2-е, 4-е, 7-е, 14-е сутки от окончания приема препарата «Офор»;

- уретрально-ректальный биэлектрофонофорез препарата «Калькулиз» (Трилон Б, лимонно-кислый калий в буферном растворе), препарата Ферменкол (1 $\mathrm{mg}$ ex tempore) и официнального раствора орнидазола (2 ml) с использованием физиотерапевтического прибора «Андророг» производства компании «Аппамед») ежедневно;

- трансректальный пневмовибромассаж предстательной железы, каждые 2-е сутки на протяжении 25 дней.

- комплекс гепатопротекторных препаратов, включая препарат «Урсоност» (урсодеоксихолевая кислота) и комплексный пробиотический препарат «Пробиз», ежедневно 25 дней.

В ходе стационарного этапа лечения не было зафиксировано значимых осложнений и побочных эффектов препаратов. Также не было случаев выхода пациентов из исследования.

После окончания лечения был проведен контроль клинического эффекта терапевтической модели (клинический и лабораторный) в двух временных срезах: инициальный (после окончания 25 дневного срока лечения) и катамнестический (через 3 месяца). По его результатам:

В общем контингенте клиническое выздоровление было зарегистрировано у 29 пациентов $(96,7 \%$ от общего контингента), лабораторное - в 27 случаях (90\% от общего контингента). Возврат симптоматики через 3 месяца был зарегистрирован у 2 пациентов $(6,7 \%$ от общего контингента).

Эффект в различных этиологических группах указан в табл. 1.

Таблица 1.

Эффект терапевтической модели в различных этиологических группах

\begin{tabular}{|l|c|c|c|c|c|c|}
\hline \multirow{2}{*}{ Этиологическая группа } & \multicolumn{2}{|c|}{$\begin{array}{c}\text { Клиническое } \\
\text { выздоровление }\end{array}$} & \multicolumn{2}{|c|}{$\begin{array}{c}\text { Лабораторное } \\
\text { выздоровление }\end{array}$} & \multicolumn{2}{c|}{$\begin{array}{c}\text { Возврат симпто- } \\
\text { матики в периоде } \\
\text { 3 мес. }\end{array}$} \\
\cline { 2 - 7 } & Абс. (N) & Отн. (\%) & Абс. (N) & Отн. (\%) & Абс. (N) & Отн. (\%) \\
\hline $\begin{array}{l}\text { Trichomonas vaginalis } \\
\text { (11 пациентов) }\end{array}$ & 10 & $90,9 \%$ & 9 & $81,8 \%$ & 1 & $10,9 \%$ \\
\hline $\begin{array}{l}\text { Mycoplasma hominis / } \\
\text { Ureaplasma urealyticum / } \\
\text { Ureaplasma parvum } \\
\text { (4 пациента) }\end{array}$ & 4 & $100 \%$ & 4 & $100 \%$ & - & - \\
\hline $\begin{array}{c}\text { анаэробная микрофлора } \\
\text { (5 пациентов) }\end{array}$ & 5 & $100 \%$ & 5 & $100 \%$ & - & - \\
\hline $\begin{array}{c}\text { аэробная микрофлора } \\
\text { (10пациентов) }\end{array}$ & 10 & $100 \%$ & 9 & $90 \%$ & 1 & $10 \%$ \\
\hline
\end{tabular}


В группе пациентов с Trichomonas vaginalis (11 пациентов): клиническое выздоровление было зарегистрировано у 10 пациентов (90,9\% от контингента группы), лабораторное у 9 пациентов ( $81,8 \%$ от контингента группы). Через 3 месяца, был отмечен 1 случай возврата симптоматики.

В группе пациентов с Mycoplasma hominis / Ureaplasma urealyticum / Ureaplasma parvum (4 пациента): клиническое и лабораторное выздоровление было зарегистрировано во всём контингенте. Через 3 месяца, был отмечен 1 случай возврата симптоматики.

В группе пациентов с анаэробной микрофлорой (5 пациентов): клиническое и лабораторное выздоровление было зарегистрировано во всём контингенте.

В группе пациентов с аэробной микрофлорой (10 пациентов): клиническое выздоровление было зарегистрировано во всем контингенте группы, лабораторное выздоровление - у 9 пациентов (90\% от контингента группы). Через 3 месяца, был зарегистрирован 1 случай возврата симптоматики.

Выводы: использование терапевтической модели с последовательным назначением препаратов «Офор» и «Гинекит» В сочетании с комплексом вспомогательной фармако- и физиотерапии в отношении пациентов, страдающих воспалительными заболеваниями предстательной железы, ассоциированных с Trichomonas vaginalis, Mycoplasma hominis, Ureaplasma urealyticum, Ureaplasma parvum, распространенной анаэробной и аэробной микрофлорой, показал общую клиническую эффективность на уровне 96,7\%. Анализ этиологической вариабельности клинического эффекта указывает на наличие единичных случаев неполного эффекта данной терапевтической модели, при этиологии заболевания ассоциированной с Trichomonas vaginalis.

\section{СПИСОК ЛИТЕРАТУРЫ}

1. Арсланов М. М., Камалов И. И., Фаттахов В. В. Физиотерапевтические методы лечения хронического простатита // Практическая медицина. 2011. № 48. С. 22-24.

2. Горпинченко І. І., Нуріманов К. Р., Сайдакова Н. О. та ін. Чоловіче безпліддя в Україні: статистика та тенденції // Здоровье мужчины. 2012. № 4. С. 132-141.

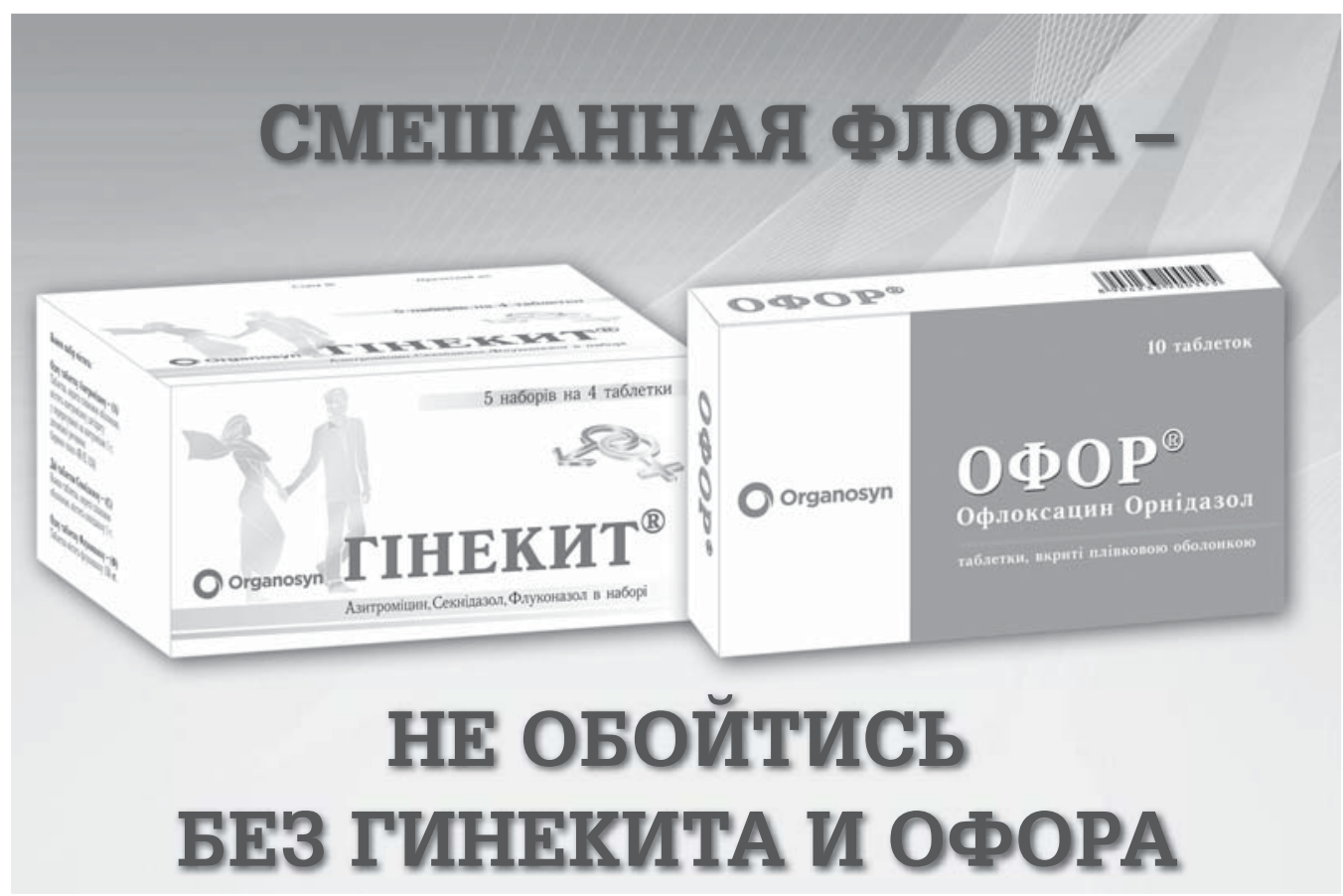


3. Горпинченко І. І., Литвинець Є. А., Сандурський 0. П. та ін. Діагностика хронічного простатиту: сучасні реалії та проблеми // Здоровье мужчины. 2014. № 1. С. 105-110.

4. Крупин А. В., Крупин В. Н. Патогенетическая терапия больных хроническим бактериальным простатитом // Современные технологии медицины. 2011. № 2. С. 168-170.

5. Мавров Г. І., Бондаренко Г. М., Іващенко Л. В. та ін. Урогенітальний трихомоноз: нові можливості топічної імуномодулюючої терапії // Дерматологія та венерологія. 2011. № 3. С. 69-77.

6. Шангичев А. В., Набока Ю. Л., Ибишев Х. С. и др. Микробный спектр и антибиотикочувствительность микроорганизмов секрета простаты при хроническом бактериальном простатите // Кубанский научный медицинский вестник. 2010. № 3-4. С. 207-211.

7. Hou D. S., Long W. M., Shen J. et akl. Characterization of the bacterial community in expressed prostatic secretions from patients with chronic prostatitis/chronic pelvic pain syndrome and infertile men: a preliminary investigation // Asian Journal of Andrology. 2012. № 14 (4).P. 566-573.

8. Krieger J. N., Lee S. W. H., Jeon J. et al. Epidemiology of prostatitis // International journal of antimicrobial agents. 2008. № 31 (1). P. $85-90$.

9. Magri V., Wagenlehner F. M. E., Montanari E. et al. Semen analysis in chronic bacterial prostatitis: diagnostic and therapeutic implications // Asian Journal of Andrology. 2009. № 11 (4). P. 461-477.

\section{PEЗЮME}

\section{ДОСВІД ЗАСТОСУВАННЯ ПРЕПАРАТІВ ОФОР I ГІНЕКІТ У ЛІКУВАННІ ПРОСТАТИТІВ, АСОЦІЙОВАНИХ ЗІ СПЕЦИФІЧНОЮ ТА ЗМІШАНОЮ МІКРОБНОЮ ФЛОРОЮ}

\author{
Ю. І. Засєда, Шихалієв Ф. Б., Солом'яний Р. І. \\ Клініка «Чоловіче Здоров'я» м Київ
}

Мета дослідження - встановити ефективність використання препаратів «Офор» $i$ «Гінекіт» при послідовному одночасному застосуванні в терапії запальних захворювань передміхурової залози, асочійованих зі специфічною та змішаною мікробною флорою.

Матеріали та методи. Проведено клінічне проспективне дослідження, в якому взяли участь 30 пачієнтів амбулаторного відділення клініки «Мужское Здоровье», які страждають запальними захворюваннями передміхурової залози. В якості методів дослідження, крім стандартного комплексу, були обрані: IN POUCH TV-тест; Андрофлор (ПЛР метод); сонографічне дослідження передміхурової залози і спермограма.

Результати дослідження. У дослідженні встановлено, що у загальному контингенті клінічне одужання було зареєстровано у 29 пацієнтів (96,7\% від загального контингенту), лабораторне -у 27 випадках (90\% від загального контингенту). Повернення симптоматики через 3 місяиі було зареєстровано у 2 пачієнтів (6,7\% від загального контингенту).

Висновки. Рівень ефективності використання препаратів «Офор» $i$ «Гінекіт» в поєднанні з комплексом допоміжної фармако- і фізіотерапії по відношенню до пачієнтів, що страждають на запальні захворювання передміхурової залози, асоційовані зі специфічною та змішаною мікробною флорою, досягає 96,7\%. Аналіз етіологічної варіабельності клінічного ефекту вказує на наявність поодиноких випадків неповного ефекту даної терапевтичної моделі, при етіології захворювання асоиійованої 3 Trichomonas vaginalis.

Ключові слова: урологія, передміхурова залоза, простатит, спермограма.

\section{SUMMARY}

EXPERIENCE OF USE OF OFOR AND GYNEKIT IN
THE TREATMENT OF PROSTATITIS ASSOCIATED
WITH SPECIFIC AND MIXED MICROBIAL FLORA

Yu. I. Zaseda, Shyhaliev F. B., Solomianyi R. I. Clinic "Men's Health" Kiev

Purpose of the study - establish the effectiveness of "Ofor» and "Gynekit» use in sequential combined application in the therapy of prostate gland inflammatory diseases, which associated with a specific and mixed microbial flora.

Materials and methods. A clinical prospective study was conducted, 30 patience of outpatient department of the «Men's Health» clinic, suffering from inflammatory diseases of the prostate gland, took part in it. As methods of research, in addition to standard complex, the following were chosen: IN POUCH TV-test; Androflor (PCR method); sonographic examination of the prostate and spermogram.

Results of the study. The study found that in the general contingent clinical recovery was registered in 29 patients (96.7\% of the total contingent), laboratory - in 27 cases (90\% of the total contingent). The return of symptoms in 3 months was registered in 2 patients $(6.7 \%$ of the total contingent).

Conclusions. The level of effectiveness of "Ofor" and "Gynekit" use in combination with a set of auxiliary pharmaco- and physiotherapy for patients, who suffering from inflammatory diseases of the prostate gland, associated with specific and mixed microbial flora, reaches $96.7 \%$. Analysis of the etiological variability of the clinical effect indicates the presence of single cases of incomplete effect of this therapeutic model, with the etiology of the disease associated with Trichomonas vaginalis.

Key words: urology, prostate gland, prostatitis, spermogram. 